\title{
Sustainability and Resilience after COVID-19: A Circular Premium in the Fashion Industry
}

\author{
Idiano $D^{\prime}$ Adamo ${ }^{1, *(1)}$ and Gianluca Lupi ${ }^{2}$ \\ 1 Department of Computer, Control and Management Engineering, Sapienza University of Rome, \\ Via Ariosto 25, 00185 Rome, Italy \\ 2 Accademia del Lusso, Via Montenapoleone 5, 20121 Milan, Italy; gianluca.lupi@gmail.com \\ * Correspondence: idiano.dadamo@uniroma1.it
}

check for

updates

Citation: D'Adamo, I.; Lupi, G. Sustainability and Resilience after COVID-19: A Circular Premium in the Fashion Industry. Sustainability 2021, 13, 1861. https://doi.org/ $10.3390 /$ su13041861

Academic Editor: Marc Rosen

Received: 2 February 2021

Accepted: 5 February 2021

Published: 9 February 2021

Publisher's Note: MDPI stays neutral with regard to jurisdictional claims in published maps and institutional affiliations.

Copyright: (c) 2021 by the authors. Licensee MDPI, Basel, Switzerland. This article is an open access article distributed under the terms and conditions of the Creative Commons Attribution (CC BY) license (https:// creativecommons.org/licenses/by/ $4.0 /)$.
COVID-19 has challenged so many of humanity's certainties, but it has also shown that we are able to react to serious threats. Moreover, it is possible to see a great opportunity: to create a real, sustainable renaissance. However, the challenge is so complex that it requires the involvement of as many categories of stakeholders as possible, and the implementation of low-carbon models in different production sectors [1].

A single closed-loop supply chain can be reconfigured as a multi-loop system, in which both reused and recycled materials from a previous life cycle are reintroduced into the market as new products and values. In particular, this editorial focuses on on the fashion industry, which unquestionably characterizes the lives of all citizens and identifies a potential circular premium.

\section{The Circular Economy Is the Cure That Can Give Oxygen to the Linear Economy and Consumption Model}

Large players in the fashion industry have the opportunity to introduce and reinforce sustainability obligations by accelerating and introducing structural changes such as reducing seasonal clothing in favor of a circular economic model. To address this type of change, they will need to reformulate their strategy by first identifying and then capturing the competitive advantage by having at their disposal sustainable policies that can foster greater resilience. As Einstein stated, ". . . it is crisis that brings progress. It is in crisis that inventiveness, discovery and great strategy are born".

The time is right to enact a much-needed change to re-invent the fashion industry. A more resilient, anti-fragile and fair future can begin in the post-pandemic period. Circularity is the asset that can surely lead to an ethical and responsible improvement on both the production and consumption sides. It must be understood that an extremely high number of garments in one's closet certainly doesn't help anyone; if anything, it adds to the growth of waste and a greater consumption of both water and energy. It is not necessarily true that a garment purchased the previous year must be thrown away. Our system of consumerism and capitalism has educated us to accept an economic a model where every week trendy fashion groups propose new collections, triggering the need for novelty to the detriment of recently purchased garments, considered outdated and not fashionable.

Circularity serves to reduce the amount of waste by preventing it from ending up in landfills or being incinerated. In order to interrupt this wastefulness in the medium-long term, it is therefore necessary to make products with eco-sustainable materials from the very beginning of production. Linked to this is the problem of finding a solution for the immense amount of waste that already exists and will continue to exist in the transition to the circular economic model.

The need to design a future of well-being through sustainable design requires immediate action. Companies can adopt many strategies: (i) reorienting purchase methods towards renting; (ii) selling garments by subscription; and (iii) repairing or regenerating a garment, thereby creating a product with an infinite life cycle. It is interesting to note 
that in this alternative business model, productive attention is not directed solely at how a product is made but rather at how it is disassembled and recycled.

We could then make this assumption: the end of the product in strategic planning is the beginning of invention: upstream a new process will be developed through which materials will not become harmful or toxic waste. The circular economy can be the means to regenerate the linear model of production and consumption.

Fashion, as Oekom Research mentioned, is one of the most polluting industries in the world, causing enormous environmental damage. Half, or nearly half, of all the clothes produced in the world are made of polyester, a byproduct of crude oil. This certainly results in a durable product, but it makes the entire production process fragile. That is why it makes sense to use of not only classic, conventional raw materials (such as cotton, jute, and silk) but also the wide range of underrated sustainable fibers. The use of these natural resources for the production of clothing is found in many cultures. For example, in some countries the highest quality clothing is produced from lotus fiber, harvested from the lotus stem, and pineapple leaves are referred to as elite fibers. This is because normal cotton production process has a negative impact on environmental sustainability. In fact, high-intensity cultivation creates high water consumption, degrades soil fertility, and leaves a carbon footprint. For this reason, it is necessary to be aware that if there is an increase in demand for consumption after COVID-19, the fashion system will have to adopt resilient production models. A possible approach is to consider how agriculture can provide organic raw materials by diversifying primary products through crops of banana, pineapple, coffee, or bamboo. In this way, sustainable and superior quality products will be created, the agricultural method will regenerate the soil, and the carbon problem will be diminished or eliminated by improved biodiversity.

\section{Consumers and Businesses Directed to Follow a Green Path}

When analyzing and studying the circular economy in the fashion industry, it is useful to consider research that highlights how consumers and companies feel about sustainability. McKinsey conducted an important survey in April 2020 (Consumer Sentiment on Sustainability in Fashion) of 2000 British and German consumers. Two-thirds of the interviewees affirmed following issues: (i) the use of sustainable materials is an important driver towards the final purchase (67\%); (ii) brands should be totally transparent about sustainability (70\%); (iii) the delay of new collections is not a problem $(65 \%)$; (iv) there is a propensity to repair items in order to prolong their use (57\%); (v) there is a frequent purchase of durable fashion items (65\%); (vi) keeping items longer (71\%). The research also shows that the target audience of Generation $\mathrm{Z}$ and millennials has a strong propensity to purchase second-hand items.

Taking into account how purchasing habits are changing, and considering the latest report of LifeGate's National Observatory on Sustainable Lifestyle, we can see that if only $7 \%$ of respondents in 2016 claimed to buy natural clothing, this sample would have increased to $16 \%$ in three years. The growth of this change is mainly driven by the younger generations (as highlighted above). The state-of-fashion report prepared by BoF together with McKinsey showed that 31\% of consumers born after 1996 say they would be willing to pay more for products with a lower environmental impact. Of these, $26 \%$ were from the generation born between 1982 and 1995 and 17\% were from Generation X. This profound attention to the need for better, sustainable goods has further promoted the concept of buy less, buy better.

This change has also led to the management of large fashion companies to start following a greener path. Companies have understood how a sustainable model can produce a competitive advantage in reputation and differentiation. For this reason, the big fashion houses are committed to developing policies that encourage and improve sustainability.

During the pandemic period, this trend has greatly accelerated. The Kering Group, for example, to which Gucci, Bottega Veneta, Balenciaga and Yves Saint Laurent belong, was selected during the Word Economic Forum as seventh out of over 8000 companies 
for its commitment to green production. Several years ago, the group has also launched a product line composed mainly of renewable raw materials. In 2018, it also published the Kering Standards: industry-leading environmental and social requirements for its brands and suppliers. Maire-Claire Daveu, the Kering Group's head of sustainability said, "Our ambition is to redefine luxury to help influence and drive these positive changes."

The LVMH group, which includes Dior, Fendi and Loro Piana, has introduced the LIFE program (actions aimed at the environmental performance of LVMH and its maisons with the goal of reducing $\mathrm{CO}_{2}$ emissions. Prada, on the other hand, supports the sustainability manifesto for Italian fashion and is a member of the Commission for Sustainability, Ecology and the Environment. It has also contributed to the guidelines on eco-toxicological requirements for clothing, leather goods, footwear and accessories that introduce parameters for the use of chemicals to improve product safety and reduce pollution. Strong in this direction is also the action of Valentino, one of the first brands to join Greenpeace's Detox protocol, a campaign to eliminate harmful chemicals from the fashion industry production chain. "Being nature-positive means being business-positive," declares Marco Bizzarri, CEO of Gucci.

\section{A Circular Premium in the Fashion Industry}

Large companies also have the advantage of having bodies or guides that highlight what models to follow to create responsible and sustainable strategies. One of the most important authorities is the Global Fashion Agenda, which is proposed annually by the Copenhagen Fashion Summit. Abolishing the "take, make, dispose" economic model would mean reducing the problem of unsold goods, which is responsible for a good $73 \%$ of garments ending up in landfills. This institution has proposed as priorities several lines to be followed, among which we highlight: (i) traceability throughout the production chain; (ii) climate change conversion; (iii) efficient use of energy and water; (iv) a safe working environment that respects universal human rights; (v) investment in innovative and sustainable fibers; and (vi) a circular strategy.

Starting from this approach, Figure 1 proposes some lines of action that could be implemented to highlight how the sustainable transition, which will affects the fashion industry, will also have resilience in other sectors $[2,3]$. Within the fashion industry, the market analyses above have highlighted how new market segments are maturing and how necessary it is to capture this change to prevent the development of disruptive approaches by competitors.

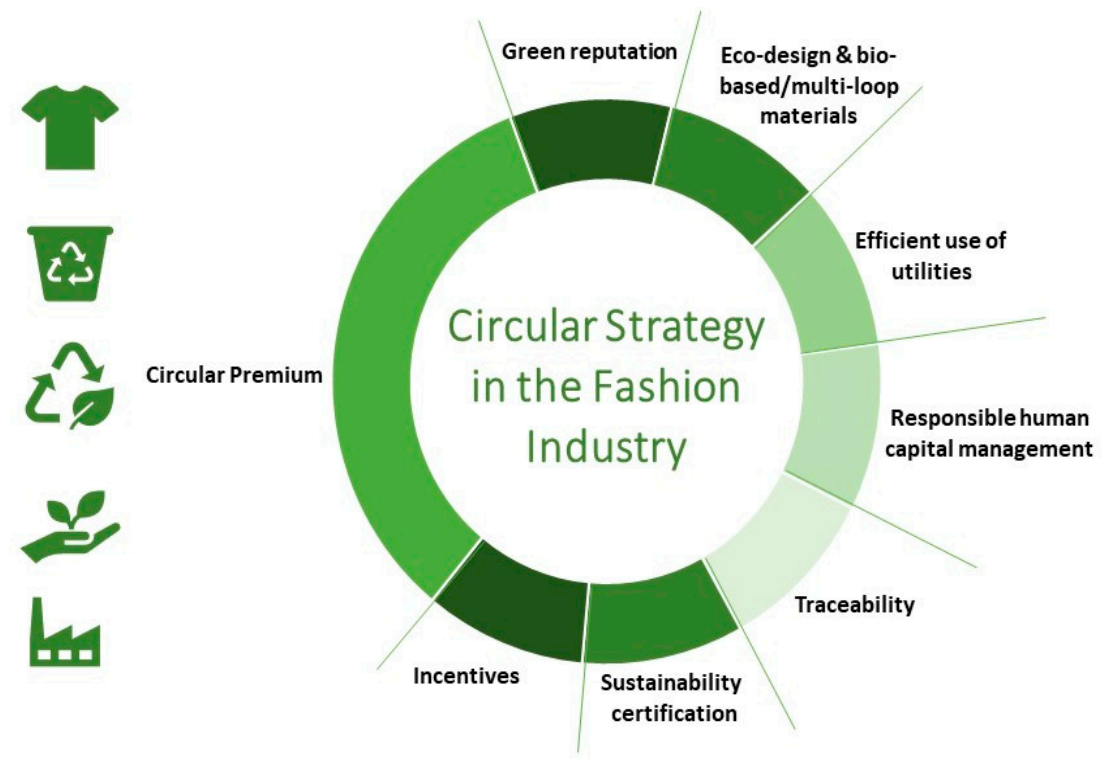

Figure 1. A circular strategy in the fashion industry. 
In order to promote a circular strategy, companies should be interested in increasing their green reputation, which not only means making changes to the supply chain, but also adopting a systemic change in which the company moves beyond its own sphere, to promote initiatives aimed at increasing community sensitivity towards the great challenge of climate change.

Regarding the specifics of the internal actions that need to be taken, eco-design is fundamental because a correct design at the beginning will allow a product to be disposed of properly at the end of its useful life. Changing the supply of raw materials is the next step because using bio-based materials will reduce the impact on other eco-systems much as the "reuse, recycle, recovery" of products already used can be re-introduced into the market to favor a multi-loop model.

The operational and distribution phases may require the excessive use of different utilities. To this end, the various textile production plants must be able to reduce water and energy consumption in addition to reducing the use and release of harmful chemicals. The action of energy efficiency can be supported by the use of energy produced from renewable sources, and the same can be done during the distribution phase through green fuels.

Human relations theory has highlighted how a mix of formal and informal factors can be identified in the organizational context. Some aspects such as health, safety, diversity and gender equality, should be ever-present requirements. This pandemic period has put the emphasis back on the relevance of human relations by fostering the concept of responsible human capital management.

Traceability makes it possible to identify where to concentrate resources, and this strategy of total transparency will allow consumers and investors to analyze the impact of their products. Digitization can aid traceability in a sector such as textiles, which is characterized by a fragmented structure. Traceability in the product realization phase is therefore very complex, but no less so for the consumer. Customer loyalty can take place in different ways, but in a circular perspective it is important to encourage the return of products that are no longer desired or usable. In the first case, the garment is given a new owner; in the second case, the materials are given a new life cycle. This can be done by returning them to stores, but also to specialized collection centers by means of agreements. Furthermore, it is necessary to investigate the relationship between traceability and e-commerce sales channels. In fact, the pandemic period has seen a propensity towards such use. Packaging plays a key role in a circular model, but future studies will need to explore the sustainability of this sales channel compared to the traditional one.

Companies called to redesign their production process to include the acquisition of natural raw materials could incur higher costs. Would consumers be willing to pay more? Thus, companies will have to balance return with risk because not making that choice could mean losing current customers as well as future ones. Consumers may be willing to accept that a circular price (i.e., the price required for a $100 \%$ bio-based product obtained with a sustainable approach) is different from the normal price (i.e., the price they currently pay for fossil fuel-based products). We can therefore introduce in the literature a new term called "the circular premium", which measures the difference between the circular price and the normal price. In addition, a further question to analyze is how to establish the relationship between the circular premium and the percentage of bio-based material in the products. The determining of this percentage will not be easy, but it is crucial to identifying which products (clothing) are truly sustainable. In addition, the circular premium may vary depending on the recipient (e.g., children) or use (e.g., underwear).

In this transition, a sustainability assessment is complex. The analysis must cover the life cycle of the whole product and be compared to a product manufactured under current conditions (totally fossil fuel-based or partially obtained from bio-based materials and renewable energies). However, the assessment cannot focus only on the environmental component; the social and human component cannot take a back seat. Sustainable certification must include these aspects in order to allow a fair comparison between companies. 
Furthermore, incentives are necessary to foster a circular model. The objective could be achieved through different but also complementary actions: producers would supply the raw materials and modify the production processes; consumers would encourage the collection of the product and do not dispose of it as undifferentiated; and third parties would set up reuse, recycling and recovery plants. Future policy perspectives will identify the most appropriate tool to foster the development of circular models. Good intentions are worthless if they are not translated into concrete actions.

"Sustainability is the organizing principle on which to build the future of the fashion industry, more resilient than ever," declared Eva Kruse, CEO of Global Fashion Agenda. The pandemic period has caused severe socio-economic damage, but it is accompanied by environmental deterioration that can also affect economic opportunities and social equity. In the face of this double risk, future generations are ready to be resilient and make their contribution not only on the consumption side but also through their inclusion in fashion companies by bringing green and circular principles with them. Policy makers can also favor this choice. We think that human strength is resilient by overcoming shocks resulting from economic crises or natural disasters when wearing clothing made form sustainable material and with rainbow colors. Sustainability allows the fashion industry to determine value not only in the aesthetic direction but also in the ethical one.

Author Contributions: Conceptualization, I.D. and G.L.; writing-Original draft preparation, G.L.; writing-Review and editing, I.D. and G.L. All authors have read and agreed to the published version of the manuscript.

Funding: This research received no external funding.

Conflicts of Interest: The authors declare no conflict of interest.

\section{References}

1. D'Adamo, I.; Falcone, P.M.; Martin, M.; Rosa, P. A sustainable revolution: Let's go sustainable to get our globe cleaner. Sustainability 2020, 12, 4387. [CrossRef]

2. Elmqvist, T.; Andersson, E.; Frantzeskaki, N.; McPhearson, T.; Olsson, P.; Gaffney, O.; Takeuchi, K.; Folke, C. Sustainability and resilience for transformation in the urban century. Nat. Sustain. 2019, 2, 267-273. [CrossRef]

3. D'Adamo, I.; Rosa, P. How do you see infrastructure? Green energy to provide economic growth after COVID-19. Sustainability 2020, 12, 4738. [CrossRef] 